AperTO - Archivio Istituzionale Open Access dell'Università di Torino

\title{
Natural iron ligands promote a metal-based oxidation mechanism for the Fenton reaction in water environments
}

\section{This is the author's manuscript}

Original Citation:

\section{Availability:}

This version is available http://hdl.handle.net/2318/1768966

since 2021-02-04T17:53:54Z

Published version:

DOI:10.1016/j.jhazmat.2020.122413

Terms of use:

Open Access

Anyone can freely access the full text of works made available as "Open Access". Works made available under a Creative Commons license can be used according to the terms and conditions of said license. Use of all other works requires consent of the right holder (author or publisher) if not exempted from copyright protection by the applicable law. 
SUPPLEMENTARY MATERIAL

\title{
Natural Iron Ligands Promote a Metal-Based Oxidation Mechanism for the Fenton Reaction in Water Environments
}

\author{
Giulio Farinelli, ${ }^{\dagger}$ Marco Minella,${ }^{\ddagger}$ Marco Pazzi,,${ }^{\dagger}$ Stefanos Giannakis, ${ }^{\S}$ Cesar \\ Pulgarin," Davide Vione, ${ }^{*,+}$ Alberto Tiraferri ${ }^{*}, \dagger$
}

†Department of Environment, Land and Infrastructure Engineering (DIATI), Politecnico di Torino, Corso Duca degli Abruzzi 24, 10129, Turin, Italy

${ }^{ \pm}$Department of Chemistry, University of Turin, Via Pietro Giuria 7, 10125 Turin, Italy

${ }^{\S}$ Universidad Politécnica de Madrid, E.T.S. Ingenieros de Caminos, Canales y Puertos, Departamento de Ingeniería Civil: Hidráulica, Energía y Medio Ambiente, Unidad docente Ingeniería Sanitaria, c/ Profesor Aranguren, s/n, ES-28040 Madrid, España

"SB, ISIC, Group of Advanced Oxidation Processes, Ecole Polytechnique Fédérale de Lausanne (EPFL), Station 6, 1015 Lausanne, Switzerland

Corresponding Authors

Email: alberto.tiraferri@polito.it; davide.vione@unito.it 


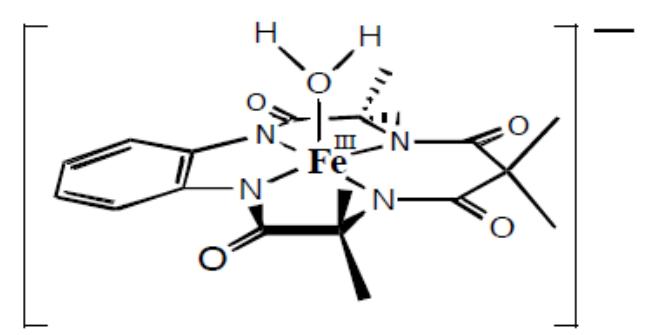

Figure S1. Fe-TAML molecular structure

Table S1. Oxidation of cyclohexane at different $\mathrm{pH}$ values with citric acid as iron ligand

\begin{tabular}{cccc}
\hline $\mathbf{p H}$ & $\mathbf{A}(\mathbf{M})$ & $\mathbf{K}(\mathbf{M})$ & $\mathbf{A} / \mathbf{K}$ \\
\hline $\mathbf{3}$ & $2.77 \times 10^{-9}$ & $2.75 \times 10^{-10}$ & 10.07 \\
$\mathbf{5}$ & $3.94 \times 10^{-9}$ & $5.37 \times 10^{-10}$ & 7.35 \\
$\mathbf{6}$ & $3.24 \times 10^{-9}$ & $3.82 \times 10^{-10}$ & 8.48 \\
$\mathbf{7}$ & $5.31 \times 10^{-9}$ & $6.16 \times 10^{-10}$ & 8.62 \\
\hline
\end{tabular}

Reactants: cyclohexane $(0.1 \mathrm{mM})$, hydrogen peroxide $(0.001 \mathrm{mM})$, iron(II) $(0.1 \mu \mathrm{M})$.

Table S2. Oxidation of cyclohexane at different $\mathrm{pH}$ values with malic acid as iron ligand

\begin{tabular}{cccc}
\hline $\mathbf{p H}$ & $\mathbf{A}(\mathbf{M})$ & $\mathbf{K}(\mathbf{M})$ & $\mathbf{A} / \mathbf{K}$ \\
\hline $\mathbf{3}$ & $1.82 \times 10^{-9}$ & $1.02 \times 10^{-10}$ & 17.79 \\
$\mathbf{5}$ & $1.65 \times 10^{-9}$ & $1.14 \times 10^{-10}$ & 14.48 \\
$\mathbf{6}$ & $4.56 \times 10^{-9}$ & $2.89 \times 10^{-10}$ & 15.81 \\
$\mathbf{7}$ & $3.47 \times 10^{-9}$ & $2.26 \times 10^{-10}$ & 15.38
\end{tabular}

Reactants: cyclohexane $(0.1 \mathrm{mM})$, hydrogen peroxide $(0.001 \mathrm{mM})$, iron(II) $(0.1 \mu \mathrm{M})$. 
Table S3. Oxidation of cyclohexane at different $\mathrm{pH}$ values with quinic acid as iron ligand

\begin{tabular}{cccc}
\hline pH & $\mathbf{A}(\mathbf{M})$ & $\mathbf{K}(\mathbf{M})$ & $\mathbf{A} / \mathbf{K}$ \\
\hline $\mathbf{3}$ & $5.54 \times 10^{-9}$ & $1.97 \times 10^{-10}$ & 28.14 \\
$\mathbf{5}$ & $5.90 \times 10^{-9}$ & $1.88 \times 10^{-10}$ & 31.29 \\
$\mathbf{6}$ & $5.02 \times 10^{-9}$ & $2.17 \times 10^{-10}$ & 23.15 \\
$\mathbf{7}$ & $2.90 \times 10^{-9}$ & $1.05 \times 10^{-10}$ & 27.70 \\
\hline
\end{tabular}

Reactants: cyclohexane $(0.1 \mathrm{mM})$, hydrogen peroxide $(0.001 \mathrm{mM})$, iron(II) $(0.1 \mu \mathrm{M})$. 
Degradation experiments were carried out in magnetically stirred beakers (the total volume of the aqueous phase was $50 \mathrm{~mL}$ ). The reaction mixture contained phenol, $\mathrm{Fe}^{2+}$ (as $\mathrm{FeSO}_{4}$ ) or FeIIITAML, $\mathrm{H}_{2} \mathrm{O}_{2}$, a reagent for $\mathrm{pH}$ adjustment $\left(\mathrm{HClO}_{4}\right.$ for $\mathrm{pH} 3, \mathrm{NaOH}$ for $\left.\mathrm{pH} 10\right)$ and, where relevant, t-butanol (TBA). At scheduled time intervals, a measured $2 \mathrm{~mL}$ sample aliquot was withdrawn from the reaction mixture and diluted 1:1 with the same volume of methanol to stop the Fenton reaction. Phenol was quantified by high performance liquid chromatography (HPLC), using a VWR-Hitachi Elite LaChrom instrument equipped with L2455 diode array detector (DAD), L2130 quaternary pump module, L2300 column oven (set at $40{ }^{\circ} \mathrm{C}$ ), L2200 autosampler (sample injection volume 60 $\mu \mathrm{L}$ ), Duratec vacuum degasser and reverse-phase column Merck LiChroCART, packed with LiChrospher $100 \mathrm{RP18}(125 \mathrm{~mm} \times 4 \mathrm{~mm} \times 5 \mu \mathrm{m})$. The chromatographic elution conditions were $\mathrm{A}: \mathrm{B}=70: 30$, where $\mathrm{A}$ is an aqueous solution of $\mathrm{H}_{3} \mathrm{PO}_{4}(\mathrm{pH} 2.8)$ and $\mathrm{B}$ is methanol, at $1.0 \mathrm{~mL} / \mathrm{min}$ flow rate. These conditions gave a column dead time of $1.2 \mathrm{~min}$ and a phenol retention time of 5.2 min. The detection wavelength was $210 \mathrm{~nm}$.

Considering that the Fenton reaction can produce both ${ }^{\bullet} \mathrm{OH}$ and ferryl (FeIV) species, and because TBA is a selective ${ }^{\bullet} \mathrm{OH}$ scavenger, the goal of this series of experiments was to get insight into the relative roles of ${ }^{\bullet} \mathrm{OH}$ vs. ferryl in the Fenton degradation of phenol. The experimental results are reported in Figure $\mathrm{S} 2$ for $\mathrm{Fe}^{2+}+\mathrm{H}_{2} \mathrm{O}_{2}$ at $\mathrm{pH} 3$ (S2a) and Fe-TAML $+\mathrm{H}_{2} \mathrm{O}_{2}$ at $\mathrm{pH} 10$ (S2b). In the latter case, it is interesting to observe that TBA had practically no effect on phenol degradation, which is consistent with the almost exclusive involvement of ferryl in the process. The opposite result was obtained with $\mathrm{Fe}^{2+}+\mathrm{H}_{2} \mathrm{O}_{2}$ at $\mathrm{pH} 3$, where the large inhibition effect carried out by TBA suggests that ${ }^{\bullet} \mathrm{OH}$ plays a key role in the traditional Fenton process. Therefore, one can conclude that ${ }^{\bullet} \mathrm{OH}$ is largely involved in phenol degradation by $\mathrm{Fe}^{2+}+\mathrm{H}_{2} \mathrm{O}_{2}$ at $\mathrm{pH}$, while ferryl operates in the presence of Fe-TAML $+\mathrm{H}_{2} \mathrm{O}_{2}$ at $\mathrm{pH} 10$. 

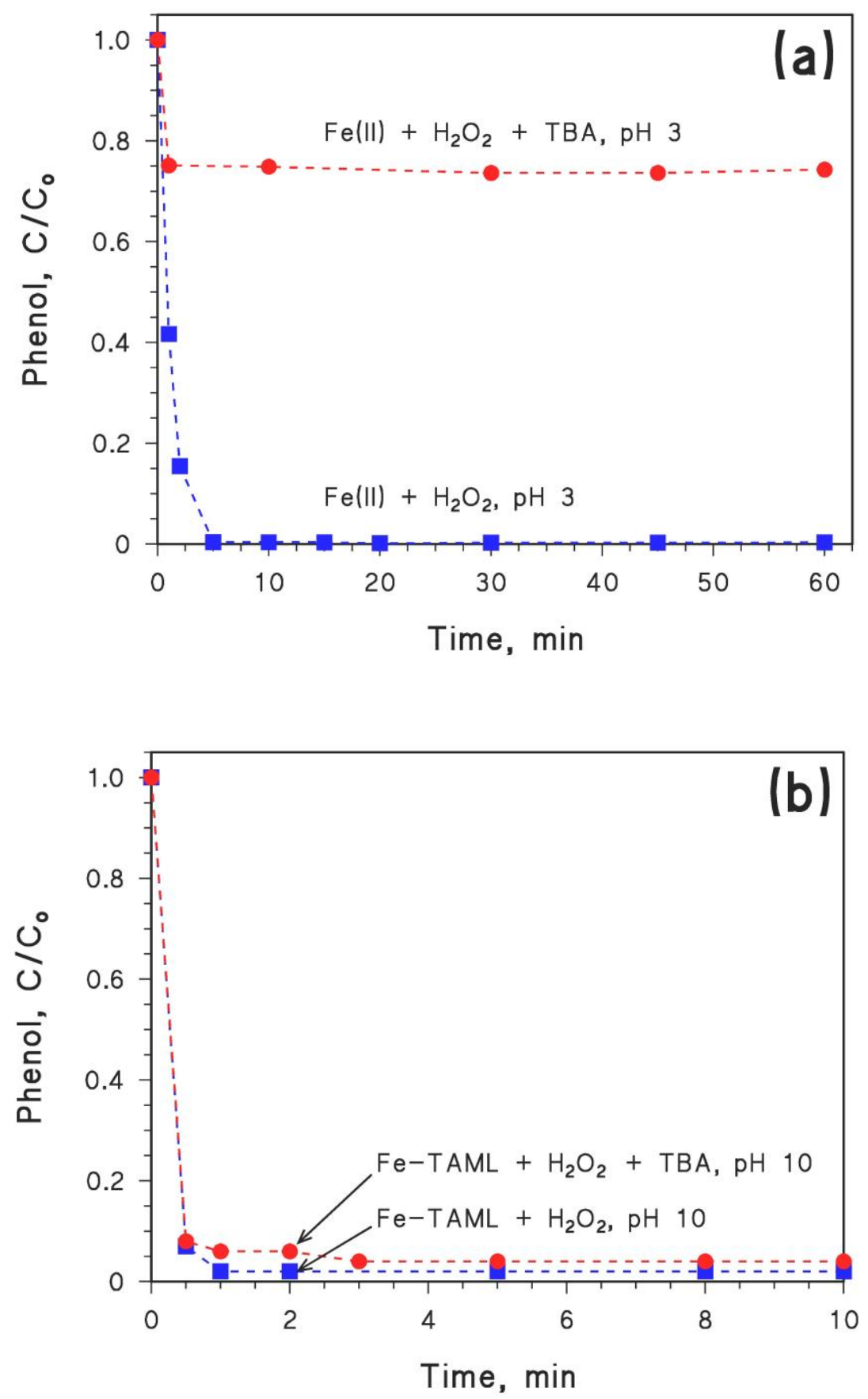

Figure S2. (a) Time trends of $0.1 \mathrm{mM}$ phenol in the presence of $0.1 \mathrm{mM} \mathrm{Fe}^{2+}$ and $1 \mathrm{mM} \mathrm{H}_{2} \mathrm{O}_{2}$, at $\mathrm{pH} 3$ by $\mathrm{HClO}_{4}$, with and without $4 \mathrm{mM}$ TBA. (b) Time trends of $0.1 \mathrm{mM}$ phenol in the presence of $0.01 \mathrm{mM} \mathrm{Fe}$ TAML and $0.1 \mathrm{mM} \mathrm{H}_{2} \mathrm{O}_{2}$, at $\mathrm{pH} 10$ by $\mathrm{NaOH}$, with and without $4 \mathrm{mM}$ TBA. 


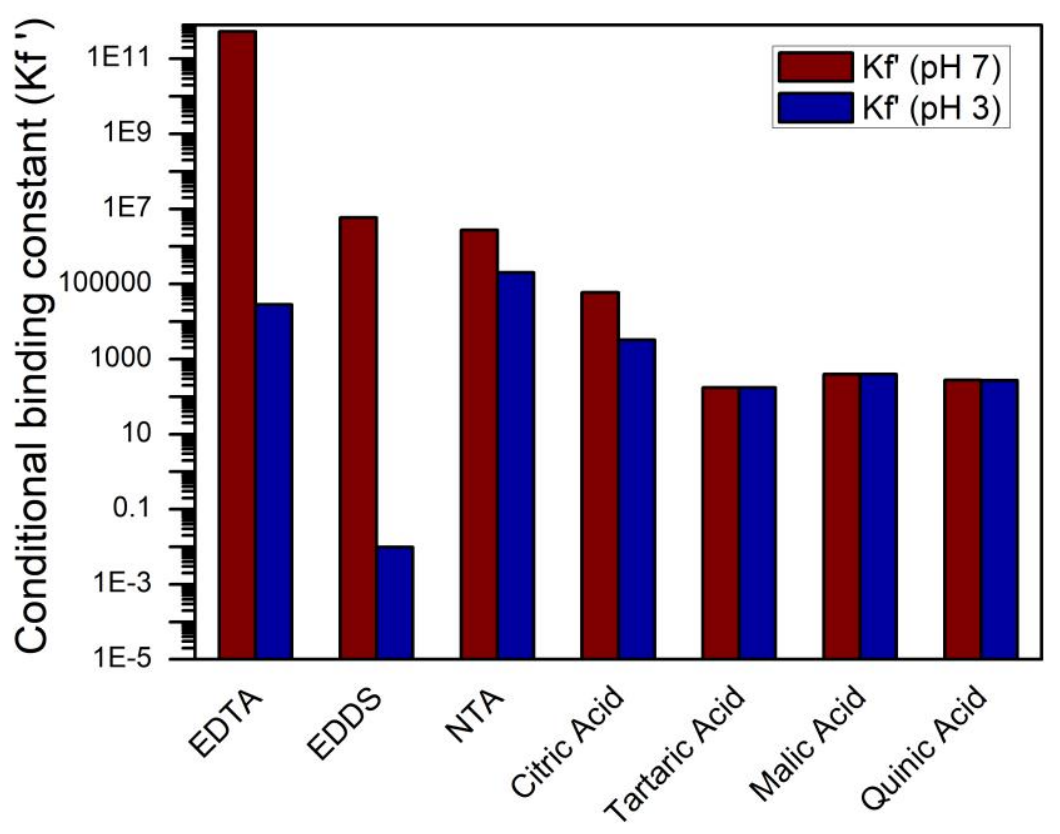

Figure S3. Conditional binding constant computed at pH 7 and $\mathrm{pH} 3$ for a variety of ligands.

The conditional binding constants for the Fe(II) complexes $[\mathrm{FeL}]^{(\mathrm{n}-2)-}$ were computed as $K_{f}^{\prime}=\alpha_{n} K_{f}$

where:

$K_{f}=$ binding constant for the ligand to metal complex with a 1 to 1 stoichiometry $\alpha_{n}=$ molar fraction of the totally deprotonated ligand species computed as

$$
\alpha_{n}=\frac{\prod_{1}^{n} K_{i}}{\left[H^{+}\right]^{n}+K_{1}\left[H^{+}\right]^{n-1}+K_{1} K_{2}\left[H^{+}\right]^{n-2}+\cdots+\prod_{1}^{n} K_{i}}
$$

where

$K_{i}=$ acid dissociation constant for the $\mathrm{H}_{\mathrm{n}} \mathrm{L}$ ligand

All the equilibrium constants were extracted from:

Arthur E. Martell and Robert M. Smith, NIST Standard Reference Database 46 Version 4.0, NIST critically selected constants of metal complexes, NIST Standard Reference Data, Gaithersburg, MD 20899 USA, 1997. 
Table S4. Oxidation of cyclohexane with EDTA as iron ligand added at different concentrations, performed at $\mathrm{pH} 3$ unless otherwise stated

\begin{tabular}{cccc}
\hline [EDTA]/[Fe(II)] & $\mathbf{A}(\mathbf{M})$ & $\mathbf{K}(\mathbf{M})$ & $\mathbf{A} / \mathbf{K}$ \\
\hline $\mathbf{0}$ & $4.86 \times 10^{-10}$ & $4.25 \times 10^{-10}$ & 1.14 \\
$\mathbf{0 . 2 5}$ & $7.32 \times 10^{-10}$ & $3.48 \times 10^{-10}$ & 2.10 \\
$\mathbf{0 . 3 7 5}$ & $1.24 \times 10^{-9}$ & $3.45 \times 10^{-10}$ & 3.60 \\
$\mathbf{0 . 5}$ & $1.29 \times 10^{-8}$ & $5.41 \times 10^{-10}$ & 23.80 \\
$\mathbf{0 . 7 5}$ & $9.87 \times 10^{-9}$ & $3.57 \times 10^{-10}$ & 27.61 \\
$\mathbf{1}$ & $9.10 \times 10^{-9}$ & $3.93 \times 10^{-10}$ & 23.13 \\
$\mathbf{1}(\mathbf{p H ~ 7 )}$ & $4.60 \times 10^{-9}$ & $1.20 \times 10^{-10}$ & 38.32 \\
\hline
\end{tabular}

Reactants: cyclohexane $(0.1 \mathrm{mM})$, hydrogen peroxide $(0.001 \mathrm{mM})$, iron(II) $(0.1 \mu \mathrm{M})$

Table S5. Oxidation of cyclohexane with EDDS as iron ligand added at different concentrations, performed at $\mathrm{pH} 3$ unless otherwise stated

\begin{tabular}{cccc}
\hline [EDDS]/[Fe(II)] & $\mathbf{A}(\mathbf{M})$ & $\mathbf{K}(\mathbf{M})$ & $\mathbf{A} / \mathbf{K}$ \\
\hline $\mathbf{0}$ & $4.86 \times 10^{-10}$ & $4.25 \times 10^{-10}$ & 1.14 \\
$\mathbf{0 . 2 5}$ & $7.88 \times 10^{-10}$ & $8.19 \times 10^{-10}$ & 0.96 \\
$\mathbf{0 . 3 7 5}$ & $8.76 \times 10^{-10}$ & $1.20 \times 10^{-9}$ & 0.73 \\
$\mathbf{0 . 5}$ & $1.14 \times 10^{-9}$ & $6.68 \times 10^{-10}$ & 1.71 \\
$\mathbf{0 . 7 5}$ & $5.81 \times 10^{-10}$ & $2.79 \times 10^{-10}$ & 2.08 \\
$\mathbf{1}$ & $6.41 \times 10^{-10}$ & $2.53 \times 10^{-10}$ & 2.53 \\
$\mathbf{1}(\mathbf{p H ~ 7 )}$ & $2.94 \times 10^{-9}$ & $6.41 \times 10^{-11}$ & 45.78
\end{tabular}

Reactants: cyclohexane (0.1 mM), hydrogen peroxide $(0.001 \mathrm{mM})$, iron(II) $(0.1 \mu \mathrm{M})$ 